\title{
Category building of international students as language learners in two secondary schools
}

\section{ANNA FILIPI}

Monash University

Abstract: This paper reports on a small scale study of category building in the context of English language learning. The data for the current study is derived from the interviews with two students, one from China and the other from Mongolia, in two schools in Melbourne. The study uses Membership Categorization Analysis to give an account of identity by examining how categories of English language learner emerge and shift during the course of the interviews. The categories established by the participants in the two interviews were constructed around different attributes belonging to the category of international student. These emerged as a series of categorical binaries including international student and local student, language competence and language deficit, mainstream English and English as an Additional Language (EAL), and home country and Australia. As the participants took part in the interview, they moved towards accounts that integrated multiple viewpoints resulting in dynamically shifting categorisations. Through these categories, it was also possible to show how students were invited to display their learning and knowledge of English, and to give accounts of their English language development.

Keywords: Membership Categorisation Analysis, identity, English language learning, international students

\section{Introduction}

The International Student Program (ISP) has become increasingly cemented in Victorian schools since it was first introduced in 1994 (Department of Education and Training (DET), n.d. a). In 2016, enrolments into the program stood at 4,337 in Victorian government schools with the majority of students originating from China, Vietnam, Saudi Arabia, India and Korea (DET, n.d. b). Yet despite these numbers and the well-established nature of the ISP in secondary schools, the program has attracted relatively 
little research interest in comparison to international students in the tertiary sector (Birrell \& Healey, 2010). In particular the voice of international students is rarely heard in investigations, one consequence of which, as Holliday (2005) notes, results in students being portrayed as 'reduced others'.

The study to be reported in this paper attempts to go towards redressing this imbalance by raising the need for further research. It is a small scale, exploratory study concerned with how students self-categorise and are categorised by others as English language learners during a research interview. The study will use Membership Categorization Analysis (Hester \& Eglin, 1997; Sacks, 1972) to analyse the data. It will be argued that understanding how international students see themselves as English language learners, how they perceive themselves to be viewed by others in terms of competence, and how others see them are important data for schools. This data can be used to make important decisions about programs, pastoral care and more effective pedagogical approaches in order to understand and address students' academic language needs.

\section{Background}

Defining identity

The question of identity has been explored from a range of perspectives in studies of the international student experience. From a socio-constructivist perspective, which is the most dominant, identity is considered to be "dynamic and variable" (Amuzie \& Winke, 2009, p. 366). It is "formed and transformed continuously in relation to the ways we are represented or addressed in the cultural systems which surround us" (Hall, 1987, p. 598), and it is "a cover term for a range of social personae, including social statuses, roles, positions, relationships, and institutional and other relevant community identities one may attempt to claim or assign in the course of social life" (Ochs, 1993, p. 288). If we accept these attributes in defining identity, then it follows that identity formation is constructed through language (Ochs, 1993; Penuel \& Wertsch, 1995), and furthermore that a primordial site for its expression and construction is social interaction (Gee, 2000; Vygotsky, 1978). By way of summarising then, using a socio-constructivist lens, identity formation is fluid and shifting, is socially shaped, and is (re)constructed through language. 
Research on identity in studies of international students

The perspective just described, and one that is particularly grounded in interaction, is largely absent from the handful of studies that have been conducted on international students in the Australian secondary school space. The studies that have been conducted can be classified in two broad strands: studies that view identity from cosmopolitanism and a transnational perspective (e.g., Matthews \& Sidhu, 2005; Wang, 2016), and those that use Bourdieu's (1977) concepts of cultural and social capital (e.g., Richardson \& Hurworth, 2007; Stafford, 2004), and his concept of habitus (Dumendon \& English, 2013). The latter group of studies has less to do with student identity formation and more to do with the "return of investment", and in the case of Dumendon and English (2013), with the impact of different cultures of learning on the pedagogical experience of an international and a refugee student.

In the studies of Matthews and Sidhu (2005) and Wang (2016), the focus is more directly on international students' experience of culture and the potential for identity reformulations. For example, Matthews and Sidhu (2005), explored how international education is linked to the aims of nurturing and developing a global identity. Their study of two schools with high numbers of international students found that such aims were left wanting. A suggested reason for their absence was the peripheral contact that international students had with local students and the marginalizing practices in the schools which were largely the result of the underlying economic drivers of the programs. In Wang's (2016) more recent study, the context was an elite, independent secondary school. By examining how international students interpreted their school's notion of the "well-rounded" individual through the attribute of participation in sports, the focus was very much on how the international student experience of reflection on themselves and on their Australian peers was perceived from a transnational and transformative perspective.

While these two investigations contribute in important ways to a sense of international student voice in schools and in how the students position themselves and others, identity per se as constantly shifting through speakers' social interactions and engagement, the driving perspective of the current study, is not a primary concern. Membership Categorisation Analysis (MCA) and conversation analysis (CA) are two approaches that are driven by such analytical concerns (Benwell \& Stokoe, 2006; Hester \& 
Eglin, 1997; Sacks, 1972, 1995). The starting point for the analyses from these perspectives is not an externally arrived at, a priori notion of identity. Rather, the analyses are conducted with reference to the local context in which identity categories are made relevant by the speakers as they interact with each other; they thus emerge through their interactions. While both approaches have their roots in ethnomethodology (see below), and are both concerned with the notion of identity as a constantly shifting, emergent phenomenon, CA is grounded in microanalysis and sequence structure. The current study is less concerned with the sequence organisation of the interactions and more with category building, the main driver of MCA.

\section{$M C A$ as a theoretical framework for the study}

MCA had its beginnings in sociology through the pioneering work of Sacks (1972), and developed as a sub-branch of ethnomethodology (Garfinkel, 1967) which is the study of the ways in which members of society make sense of their social worlds. A fundamental concept in MCA is the notion that members of society are assigned or invoke a number of social categories (for example, mother which might be understood in its collocation to child or to father or to woman). These identity categories are both based on and regulate speakers' relationships with each other. They also emerge locally as speakers interact with each other making particular social identities relevant (Hester \& Eglin, 1997). According to Stokoe (2010), these identities can be "claimed, resisted and otherwise put to use in social interaction." (Stokoe, 2010, p. 428). They therefore achieve specific social actions.

Several researchers have applied MCA to educational contexts. Benwell and Stokoe (2002, 2005) and Stokoe, Benwell and Attenborough (2013) for example, have examined how the categories of 'teacher' and 'student' are constructed in a university setting, and how they emerge in interaction to reveal rights and access to knowledge the speakers lay claim to (Sacks, 1995; Stokoe et al., 2013). Benwell and Stokoe (2005) show how the teachers' rights to initiate talk through questions that cast students in the role of responding, can be resisted by students through the action of withholding a response. Bridges and Emerald (2013) used MCA to explore the attributes that contributed to categorisations of "Native-speaking English Teacher" and "Local English Teacher" in Hong Kong. They tracked how these categorisations were 
negotiated and constructed using an interview text. Moving closer to home, Chuang (2017) examined how demonstrator and student roles were established in the opening stages of a first year university anatomy laboratory. In acknowledging that participants embody multiple identities in addition to student/demonstrator, Chuang showed how participants enact and make relevant their identities in the activities of the laboratory's social and pedagogical space, and how these shift according to the pedagogical agenda.

In the educational context discussed in this paper, the analytical interest is on how the categories and attributes of "international student" are framed, resisted and negotiated throughout the interview. The analysis will focus on examining the interactional details of participants' work in invoking and constructing dynamic and shifting identities relevant to international students using the transcripts of the interactions in two interviews. MCA is useful as a tool because it provides a method for analyzing and interpreting the identities of speakers as they categorise themselves and are categorised by the interviewers and the teacher through interaction. In this respect the analysis of the data will provide a 'thick description' (Geertz, 1973).

\section{Details of the study}

\section{Participants}

The data in the current study, which is part of a larger investigation into the ISP, is derived from two 45 minute interviews with two students, Huan and Odval, from two schools in Melbourne. One school is an outer suburban independent school with a very large international student cohort (consisting of over 100 students) and the other is an inner suburban government school with a very small cohort of four international students. At the time of the interviews, Huan, from the outer suburban school, was in year 10 and had been in Australia for three terms so just under a year; Odval, was in the final year of secondary school, year 12, and had been in Australia since 2014. Present in the interview with Huan were one interviewer, Huan and his English as an Additional Language (EAL) teacher. At the interview with Odval were Odval and two interviewers.

Segments from the two interviews that discussed language were selected for analysis. These were analysed by tracking the categories being invoked, resisted and claimed by the two interviewers, the teacher present in the first interview and the two 
international students as they interacted; and by analysing the categorical binaries or Standard Relational Pairs (SRP), which Sacks (1995) describes as a pairing of categories that are heard as "going together". Notations used in the transcription are from Conversation Analysis and published in the Australian Journal of Communication (2013). Pseudonyms or general categories have been used in the transcripts to protect the identity of the participants and institutions.

\section{A caveat}

It is important to recognise that the interactional dynamics of the interview itself strongly influence the data captured. Therefore, there is a caveat on the analysis which needs to be acknowledged. In ethnomethodological accounts of interaction, interview methods for getting at data are criticised on the grounds that responses and accounts provided in the interviews are viewed from an interviewer's interpretation of an issue. This is seen as "interfering" with data collection because the topics discussed are determined by the interviewer. Stokoe and Edwards (2006, p. 57), for example, in talking about such limitations on the elicitation of stories, state that such approaches do not take "into account as part of the analysis ... the situated, artifactual nature of researcherelicited accounts, but treat interviews as 'resource' rather than "topic". The danger in eliciting accounts lies in restricting and negating the interviewee's interactional motivations in responding. These limitations are acknowledged. However, as Deppermann (2013) argues, the interview is nonetheless a legitimate social interaction as well as a text, one that takes place in a number of institutional contexts. As Deppermann further argues, when the research approach is to view the interview as social interaction rather than as text or resource, it can be particularly useful in revealing categories as participants present, resist and negotiate stances to each other, themselves and issues under discussion even within the limitations on topic that are imposed.

\section{Analysis and discussion}

The analyses below will be focused largely on a single case, the interview with Huan, with further, albeit brief, examples drawn from the interview with Odval. The first extract comes after the interviewer has completed the introductory discussion with another student, Bingjie. 
Extract 1: Interview with Huan (denoted by $\mathrm{S} 1$ in the transcripts) in the outer surburban secondary college, his EAL teacher ( $\mathrm{T}$ in the transcript) and the interviewer (In1 in the transcript). A second student (Bingjie) is also present (denoted by S2).

1 In 1: ...and would you like to tell me a little bit about yourself too,

2 where you've come from and your en- your previous experience with

3 English?

$4 \mathrm{Sl}$ : 'yeah', I come from China, ah Guangdong province,

5 Inl: ${ }^{\circ} \mathrm{mm}^{\circ}$,

$6 \mathrm{Sl}$ : a- a- developed ah province in China, and I use- I ah have learnt

$7 \quad$ English from my primary school and then just keep going.

8 Inl: ${ }^{\circ} \mathrm{mm}^{\circ}$

9 and then while I'm preparing for the studying overseas, I used

10 to get the tutoring from other teachers and prepare for the- IELTS

11 text, so I spent a lot of time in preparing my English and then

12 improve a lot. and after arriving in this ah in Australia, >I've

13 been here for nearly three terms<,

14 Inl: $\mathrm{mm} \mathrm{hm}$,

$15 \mathrm{Sl}$ : so it's a long time and I just ah it's better for me for my

16 listening?

17 Inl: $\mathrm{mm}$,

$18 \mathrm{Sl}$ : because I need to focus on what my teacher is saying.

$19 \mathrm{Inl}: \mathrm{mm} \mathrm{hm}$,

$20 \mathrm{Sl}$ : and, also, the speaking is improved a lot because I need

21 to communicate with others.

22 Inl: $\mathrm{mm}$,

$23 \mathrm{Sl}$ : and $\mathrm{s}-\mathrm{mm} \cdot \mathrm{hh}$ [ah

24 T: [I'd say your writing has improved a lot too.

$25 \mathrm{Sl}$ : >yeah [yeah yeah<

26 S2: [huh huh

27 Inl: [as well yeah.

$28 \mathrm{Sl}$ : I just finished article about 2000 words maybe, this

29 Inl: woh!

$30 \mathrm{Sl}$ : this morning.

31 Inl: very good!

$32 \mathrm{~T}: \quad$ is that mine?

$33 \mathrm{S1}$ : yeah. I just sent it to you.

34 Inl: huh huh huh

$35 \mathrm{~T}$ : ( ) 2000. he makes me work, I tell you. no one else gives

36 [me 2000 words 
$37 \mathrm{Sl}$ : [huh huh

38 S2: [huh huh

$39 \mathrm{~T}$ : he's als- you can also ex- maybe explain about how you've been in 40 mainstream English, too, not just EAL.

In asking Huan to say something about himself, the interviewer nominates language (his previous experience with English) as a principal frame and attribute for the self-introduction. So from the very beginning, English language learning is made relevant as an identifying marker for the discussion with Huan and for his membership categorization as an English language learner. Huan responds to the request by building an image of his personal history as a learner of English and of his developing competence. He speaks of the time invested in the study of English as preparation before coming to Australia. He then talks about the benefit of being in an Australian school for both his speaking and listening skills which he has highlighted as skills that have improved. At this point his teacher counters with an evaluative statement about the improvement in his writing as well which provides an opening for Huan to strongly agree and then to go on to provide evidence for this assertion - I just finished an article about 2000 words maybe. This statement receives a very strong reaction and positive assessment ${ }^{1}$ from the interviewer woh and very good. The teacher continues to categorise Huan as exceptional through a positive assessment syntactically addressed to the interviewer but for Huan to hear as well which is delivered in a jocular manner (he makes me work...no one else gives me 2000 words). The compliment and ensuing laughter produced by all three participants work to create cohesion and affiliation between the speakers (Golato, 2005). The compliment also allows the teacher to create a further opportunity for Huan to continue to build the category of a competent English learner when she tells him to explain that he is in the mainstream English class. This is clearly an achievement - he is not just in EAL. Here the first categorical binary or Standard Relational Pair (SRP), is established between English as mainstream and English as an Additional Language.

As the interview continues, Huan turns to the topic of the language difficulties he experiences.

$41 \mathrm{Sl}$ ah mainstream English? ah it's quite hard to get to engage in the 
44 Inl: yeah,

45 S2: yeah,

$46 \mathrm{Sl}$ : and the classmate is not so familiar with - because they are local

47 [students

$48 \mathrm{Inl}:[\mathrm{mm} \mathrm{hm}$,

$49 \mathrm{Sl}$ : and only two international students [( ).

50 Inl:

[so only two of you in that

51 class?

52 S1: yeah,

53 Inl: $\mathrm{mm}$ !

$54 \mathrm{Sl}: \quad$ ( ) ${ }^{\circ} \mathrm{yeah}^{\circ}$.

55 Inl: ${ }^{\circ} \mathrm{mm}^{\circ}$,

56S1: so it's quite hard for me, but now I'm trying to get used to it

$57 \quad$ cause

58Inl: ${ }^{\circ} \mathrm{mm}^{\circ}$,

59 ah

$60 \operatorname{Inl}: \quad[(\quad)$

$61 \mathrm{Sl}$ [now I can catch up what the teacher is saying and

We see that Huan differentiates himself from the majority of his classmates by invoking local and international student categories. This is a second categorical binary which is related to the first: mainstream English (for local students) and EAL (for international students), at least initially until a level of competence is reached, which Huan clearly has. In drawing attention to this makeup of the class, he appears to be pointing to the fact that his difficulties in keeping up with the teacher may have a basis in the lack of teacher accommodation and adjustment that are features in a class with large numbers of international students. The interviewer, however, focuses on the small number of international students through her confirmation request in lines 50-51. He reiterates his point that being in mainstream English is hard. However, at the end of this turn we also note a return to the topic of his competence - now I can catch up what the teacher is saying. The temporal references to first (line 42) and now (line 56), help Huan to construct his self-image as a developing English language speaker. He is one of only two who has reached a level of competence that enables him to belong in mainstream English. English language competence is thus a category attribute. 
However, the interviewer is focused on the linguistic difficulties again, which she orients to as an attribute of the category international student rather than the attribute of competence.

62 Inl: yeah. what's the hardest part? listening and keeping up? is that

63 the hardest part? what's the hardest part?

$64 \mathrm{Sl}$ : no. I think it's the- the big ( ) gap between me and the other

65 students

66 Inl: ${ }^{\circ} \mathrm{ok}^{\circ}$.

67 because I need to spend a lot of effort to catch up with what they

68 ah to them. and can speak

$69 \mathrm{Inl}: \mathrm{mm}$,

$70 \mathrm{Sl}$ : and write

71 Inl: $\mathrm{mm}$,

$72 \mathrm{Sl}$ : freely and think what the text is about,

73 Inl: $\mathrm{mm}$,

$74 \mathrm{Sl}$ : but I can't

75 Inl: $\mathrm{mm}$,

$76 \mathrm{Sl}$ : because my language- I still need to use the basic English to ma-

77 to express what I'm thinking.

$78 \mathrm{Inl}: \mathrm{mm}$,

$79 \mathrm{Sl}: \quad$ sometimes it's hard to express my feelings about the textbooks.

The interviewer homes in on the student's earlier stated difficulty with listening and keeping up. She thus returns to the category of international student and the attribute of language difficulties, with which the student affiliates in his response. He mentions the gap between himself and the others, creating a further binary, and proceeds to create a picture of what "they can do" in opposition to what he "can't do" through his lexical choices - I need to spend a lot of effort, they can ... but I can't... I still need to use the basic English...sometimes it's hard to express. In this discussion, however, there is evidence of an important metacognitive skill, person knowledge, which is a student's ability to think about his own learning (Vandergrift \& Goh, 2012). This skill is an attribute of the competent learner category.

The topic of difficulties with English continues in this next series of sequences.

80 Inl: and why is that hard, that you don't feel as though you have ENOUGH 81 vocabulary? 
82 S1: yeah,

83 Inl: or is it the type of vocabulary? what's the problem.

$84 \mathrm{Sl}: \quad$ it's about the vocabulary,

85 Inl: yeah,

$86 \mathrm{Sl}$ : because I learnt when I'm preparing for the the IE- IELTS exam for

87 the reading part

$88 \mathrm{Inl}: \mathrm{mm}$,

$89 \mathrm{Sl}: \quad$ I focus on the sup- specific words, like they use in science and

90 Inl: yeah,

$91 \mathrm{Sl}$ : other course.

We note that Huan interprets the interviewer's first question as a yes/no question as his response yeah in line 82 indicates. The interviewer follows this up with two questions - a yes/no 'or question' and an open question in the same turn (line 83) that attempt to go to the heart of the nature of the problem with vocabulary. In Huan's response to this question, he focuses on what he has learned and how he applies what he has learned to vocabulary. By focusing on his skills and strategies, and their application, he returns to the category of competent English language learner. This is achieved by talking about the strategies he has used in the past to accomplish a reading task (in the IELTS test), a strategy he still uses now. Here he is providing evidence of yet another metacognitive skill, strategy knowledge (Vandergrift \& Goh, 2012), which is knowing about strategy use.

In the final set of sequences, the interviewer is still pursuing a more adequate understanding of what the issues in vocabulary learning might be.

92 Inl: so specific content words but [

$93 \mathrm{Sl}:$

[yeah,

94 Inl: in English it's

$95 \mathrm{Sl}$ in English I need to focus on more on the describing- describing

$97 \quad$ your emotions and yeah.

98 Inl: and you find that more difficult than science vocabulary?

99 s2: yeah,

100Inl: yeah?

101S1: because sometimes it's ah just like mm sometimes the degree of to

102 express my feeling is quite hard,

103Inl: $\mathrm{mm}$,

104S1: cause, like, the word mm hate and dislike sometimes ah it's ah a 
105 little bit different.

106Inl: okay. so it's a little bit more sophisticated vocabulary, 107sl: yeah,

108T: $\mathrm{mm}$,

109Inl: and some of the differences between those two words

110sl: yeah,

1llInl: can be quite complex, so understanding

112S1: yeah,

113Inl: those differences is the issue. that's interesting, isn't it?

114T: $\mathrm{mm}, \mathrm{mm}$,

115Inl: so

116T: but he does an excellent job.

117Inl: 'yeah',

118T: $\quad$ yeah, because in most cases, students will just take dislike it and

119 use it without understanding that there IS a difference. I mean that's

120 from Huan's point of view...

...

124Inl: [so you actually look for words, that's what you're saying,

125T: $\mathrm{mm}$,

126 isn't it?

127 that you're actually thinking about

128S1: yeah,

129 how you might develop

130s1: yeah

131Inl: your vocabulary in [C )

132S1: $\quad$ [yes because in Eng-

133Inl: your vocabulary in a more sophisticated way.

1341S2: yeah because in English I can learn more and then using the EAL

135Inl: yeah

136S1: to improve my score.

137inl: yeah,

138S1: and my writing.

139Inl: yeah

140T: he's actually just done Macbeth, in English

14lInl: oh!

142T: and asked me, and I'm like ah! [huh huh

143Inl: [huh huh

144Inl: so did you enjoy Macbeth? huh huh ah! Shakespearean-

145S2: not so much, huh huh

146All: huh huh huh

147S1: but the story is good. 
148In1: the story is good.

149S1: yeah,

150Inl: huh but the language even for us, [the language is151T:

[yeah, the language is tough.

The interviewer asks about the differences between science and English with respect to difficulty and challenges in vocabulary. In his response, Huan continues to build his self-image as a competent English language learner. He uses the example of the synonyms of dislike and hate, and refers to his difficulty in understanding the nuances in word meaning. In doing so he provides further evidence of strategy knowledge. We note that his teacher again draws attention to his excellent skills in lines 116, 118 and 119. She underlines the fact that other students would not even notice such distinctions. This action once again differentiates him from the 'other' students and in so doing creates an ever more growing picture of Huan's competence as a student. As the interview continues, there are further increments to this image occasioned by himself and by the teacher. Huan speaks about how his presence in mainstream English enables him to learn more while in EAL he is afforded opportunities to consolidate (lines 134-138). His teacher then mentions that he has just studied Macbeth. She indexes this as a challenging text. This is made evident by her own actions - her laughter, her assessments, the difficulties she had - as well as by the interviewer's reactions.

One final categorical binary is proffered in the interviewer's assessment of the linguistic challenges of reading Macbeth in her interrupted turn which is collaboratively completed (Lerner, 1996) by the teacher - but even for us, the language is ... tough. This categorises the student as a non-native English speaker on the one hand but it also adds to the category of the competent English language learner. Clearly then tackling Macbeth is a significant achievement, and the laughter of all participants is used to herald the achievement, and to establish agreement and affiliation. (On laughter as affiliation see Glenn, 2013.).

Similar categorical binaries and categorisations are evident in the interviews with the other students as well; however, in the interests of space, only relevant segments from the interview with one other student, Odval, from the inner suburban secondary college will be briefly drawn on here to further elaborate these findings. 
As we will see in the following segments, the categorisations of Odval shift from student with English language deficits to competent English language learner and speaker.

Extract 2: Interview with Odval (denoted by S3 in the transcripts) in the inner suburban secondary college and two interviewers (In1 and In2 in the transcript).

1 Inl: so let's just start by you telling us something about your[self.

2 S3:

[ok.

3 Inl: where you come from and

4 S3: $\quad$ ok. my name is Odval and I am from Mongolia. $>^{\circ}$ you guys know where

$5 \quad$ Mongolia is right? ${ }^{\circ}<$ yeah and I have been here since $2014 \ldots$

$\cdots$

9 yeah so that's why like when I first started going to school, like

10 year 11, I was- I was considered as an international student?

In introducing herself, Odval orients to the interviewers' possible lack of geographical knowledge about where Mongolia is located. It is delivered in talk that is prosodically quieter and faster than the surrounding talk, marking it as being slightly off main topic (Filipi, 2009). Odval is categorizing Mongolia as a place that is not well known in the world. ${ }^{2}$ So she is "othering" her place of origin. As an action this serves to set up an attribute for the assigned category international student. However, interestingly, in invoking this category, she presents it as a categorisation imposed by others. We note, for example, the use of the passive voice in the formulation I was considered as an international student rather than I was/am an international student. So already at the start of the interview we see a resistance to the category through lack of agency that the use of passive voice engenders.

\footnotetext{
37Inl: $\quad$... so what have been some of the challenges?

38S3: challenges?

39Inl: $\mathrm{mm}:$,

40S3: okay like at first like I can't really speak English, so

41 that's really hard. like ( )

42Inl: $\quad$ so you came here without any English at all or?

43S3: like I know ABC you know and a little bit like say hi, my name or

44Inl: $\quad$ so very, very basic.
} 
45S3: yeah basic.

46Inl: [at school]

4753: [C ) yeah, I used to study English in school, but that wasn't

48 really good in Mongolia and then yeah, and then I came here

49 and learned more English.

The interview progresses beyond the story of Odval's arrival though a shift in topic to "challenges". The interviewer's lexical choice here potentially negatively frames the experience through a focus on the difficulties. Odval does indeed orient to this through an account of her early inability to speak English. Initially this framing continues with the development of the topic: the less than adequate exposure to English language learning in Mongolia leading to deficits in Odval's English - I know the ABC and a little bit, that wasn't really good in Mongolia. By ending this turn in line 48 with and then I came here, Odval is announcing a change in her English language competence as a result of her move to Australia. This creates another categorical binary: Mongolia (basic English language learning that was inadequate) and Australia (pronounced English language development).

50 In2: your English is good.

51 S3: thanks.

52Inl: yeah very good and in such a short time!

53Int2: yeah

54S3: $\quad$ yeah and like at first I had a problem with English, so

55 understanding my teachers, what are they teaching, and then like the

56 transition period. that was really hard because so everything is

57 really different from Mongolia. like education system, how they

58 teach you, how like kids like like other students, like so

59 different. then it took me a little bit while to like adjust to it.

60 then now I think I've got like started really like you know being a

61 part of it. I think at first like I didn't know English, so it's

62 like really hard to like be friends and find friends with them like

116 ... I really want to improve my English. so I decided to read

117 books. then I start reading books last year...

...

121 like in five months I think I read like 100 books or something in

122 English.

123? ("in English ${ }^{\circ}$ ?)

124S3: huh yeah I think that helped a lot, 
125Inl: $\mathrm{mm}$ !

126S3: that was really good. also like I like to watch um like serials in

127 English.

128Inl: $\mathrm{mm} \mathrm{hm}$,

129S3: so and then like I think that helps me with my listening and also

130 like the pronunciation.

As the interview continues, the interviewers take time out from asking questions to provide a positive assessment. This is initiated by the second interviewer in line 50 through her - your English is good with prosodic emphasis on good. This receives a second assessment and agreement by the first interviewer who further comments on the short length of time that it has taken Odval to develop her English language competence. The student accepts the interviewers' compliments (lines 51 and 54), and indeed orients to the compliment as an invitation to display how she has developed her English language skills as we saw Huan do (lines 54-62).

The focus for both students is on the strong motivation to improve their English and on the strategies deployed to achieve this personal goal. We also have a very clear invited display of the knowledge that both students have acquired and of what makes a good learner per se, as well as a good English language learner more specifically. In this process, the category of student with English language deficits has been replaced with both competent learner and competent English language learner.

\section{General discussion and conclusions}

Summary of findings

As stated earlier, MCA enables an examination of categories that emerge in interaction to reveal rights and access to knowledge the speakers lay claim to (Stokoe et al., 2013). By applying an interactional perspective afforded by MCA to investigate how the international students, the teacher and the two interviewers built understandings and created spaces for student displays about their English language and their academic learning, we see how they have each participated in category building.

There is no doubt that the interview imposed an agenda on the participants. This was evident in the ways in which interviewer 1 in particular adhered to the script of the set questions and the purpose of the interview which was to determine a range of issues about the International Student Program. Nonetheless, the 
interview became an opportunity for participants to make knowledge claims about what it means to be an English language learner, a learner and an international student, as participants drew on their personal lived experiences and assumptions to accept, contest and negotiate these claims.

Throughout the interview, language was named as a category and as an identifying marker for the discussion with the two students and their membership categorisation as English language learners. The categories invoked in category building were constructed around different sets of attributes which were presented as a series of categorical binaries. The analytic work involved in examining the binary category systems of international and local, language competence and language deficit, mainstream English and EAL, home country and Australia as established by the participants in the two interviews, showed how the participants moved between accounts that integrated multiple viewpoints resulting in dynamically shifting categorisations. In building these categories, all participants were involved in collaborating to open a space for the students to invoke their personal histories, and to tell stories about their current experiences with reference to themselves as being both different from and the same as the other students. In this process, ways in which the participants worked to achieve affiliation with each other was clearly in evidence.

\section{Implications arising from the findings in the study}

While the study was principally concerned with identity categorisation, the findings that have emerged have relevance for teaching, particularly with respect to metacognitive principles. Through interview interactions, students were provided with an opportunity to reflect on their learning, and to make explicit how they went about working on their language skills. Such reflections have been shown to be important in the development of metacognition. For example, Flavell's 1979 (cited in Vandergrift \& Goh, 2012) distinction between person, task and strategy knowledge has provided a solid foundation for developing metacognitive pedagogies in EAL to support students' listening, reading and writing skills (e.g., Carrell, Gajdusek \& Wise, 2001; Goh, 1997, 2012; Kasper, 1997). Person knowledge (which relates to students' beliefs about their own learning) and strategy knowledge (which involves thinking about strategies used to accomplish a task) emerged throughout the interactions, pointing to the importance of providing a space for explicit interactions in 
teachers' learning plans. EAL teachers could for example include regular spoken briefings with individual students to discuss how they have gone about a specific task and what they intend to do next. Like the tools of diary keeping by students in listening (Goh, 1997) and the written autobiographies for reflections on writing (Kasper, 1997), such an approach would entail effective teacher feedback opportunities and scaffolding necessary for improvements in learning, best developed through self-regulation (Goh, 2010). It would also give the teacher valuable information about individual learners' strategy use and style of learning (Vandergrift \& Goh, 2012) to inform teaching.

In closing, the limitations of the study in drawing on only two interviews for its findings and conclusions need to be acknowledged. However, the "thick" analyses (Geertz, 1973) made possible through MCA have uncovered how the two international students co-produced relevant accounts of themselves by recalling their past and present experiences as learners of English and as competent students. In so doing, the study suggests a research space for the application of interactional micro-analyses in understanding how learners define or build categories of themselves, how these shift and are collaboratively constructed, and how students reflect, understand and display their knowledge about how they learn to be effective English language learners when given the opportunity to do so. Such insights are important for schools as they can be used to help them to recognise the significant learning that takes place in a short amount of time, and to understand from students themselves what they do that contributes to their learning. These understandings can then be used as the basis for effective instruction and to position schools to more effectively assist international and EAL students to develop their English language and general skills in explicit and pedagogically impactful ways.

\section{Endnotes}

1. On assessments in interaction, see Pomerantz (1984).

2. Indeed, her mathematics teacher in a separate interview does note that it is exotic in the sense that not many students from that part of the world participate in the ISP when he states "now, I have never met anyone from Mongolia before. I'm pretty sure the kids around here wouldn't have either". 


\section{Acknowledgement}

I would like to thank the Department of Education and Training Victoria for giving me permission to collect data in schools, and the schools and students who participated in this study.

I would also like to thank the anonymous reviewers for their insightful comments in reviewing this paper.

\section{References}

Australian Journal of Communication, (2013) 40(2), http://austjourcomm.org/index.php/ajc/article/ view/29/131.

Amuzie. G. L., \& Winke. P. (2009). Changes in language learning beliefs as a result of study abroad. Michigan State University, Second Language Studies, Department of Linguistics and Languages, A-711 Wells Hall, MI 48824-1027, USA.

Benwell, B., \& Stokoe, E. H. (2002). Constructing discussion tasks in university tutorials: Shifting dynamics and identities. Discourse Studies, 4(4), 429-453.

Benwell, B., \& Stokoe, E. H. (2005). University students resisting academic identity. In K. Richards \& P. Seedhouse (Eds.), Applying conversation analysis (pp. 124-139). New York: Palgrave Macmillan.

Benwell, B., \& Stokoe, E. H. (2006). Discourse and identity. Edinburgh: Edinburgh University Press.

Birrell, B. \& Healy, E. (2010). The February 2010 reforms and the International student industry. People and Place, 18(1), 65- 80. Bourdieu, P. (1977). Outline of a theory of practice. Trans. R. Nice. Cambridge: Cambridge University Press.

Bridges, S., \& Emerald, E. (2013). Intersecting global and local: The intercultural and intersubjective constructions of "expatriate" and "local" teachers in the search for the " $\mathrm{x}$ factor." Pedagogies: An International Journal, 8(4), 316-335.

Carrell P.L., Gajdusek L., Wise T. (2001) Metacognition and EFL/ ESL reading. In H. J. Hartman (Ed.), Metacognition in learning and instruction. Neuropsychology and cognition, vol. 19 (229-243). The Netherlands: Springer.

Chuang, M-S. K. (2017). Micro-analysing anatomy laboratory pedagogy.

Unpublished doctoral dissertation, Monash University.

Department of Education and Training (n.d.a). Retrieved from: http://www.education.vic.gov.au/school/principals/ management/Pages/program.aspx. 
Department of Education and Training (n.d.b). Summary statistics Victorian Schools Flyer. Retrieved from: http://www.education. vic.gov.au/about/department/Pages/factsandfigures.aspx.

Deppermann, A. (2013). Interview as text vs. interview as social interaction. Forum Qualitative Sozialforschung / Forum: Qualitative Social Research, 14(3) art.13.

Dumendon, I. E., \& English, R. (2013). Fish out of water: Refugee and international students in mainstream Australian schools. International Journal of Inclusive Education, 17(10), 1078-1088.

Filipi, A. (2009). Toddler and parent interaction: The organisation of gaze, pointing and vocalization. The Netherlands/Philadelphia: John Benjamins.

Garfinkel, H. (1967). Studies in ethnomethodology. NJ: Prentice Hall Inc.

Gee, J. P. (2000). Identity as an analytic lens for research in education. Review of Research in Education, 25(1), 99-125.

Geertz, C. (1973). The interpretation of cultures. London: Hutchinson.

Glenn, P. (2013. Interviewees volunteered laughter in employment interviews: A case of 'nervous' laughter?, In P. Glenn \& E. Holt (Eds.), Studies of laughter in interaction (225-276). London, UK: Bloomsbury Academic.

Goh, C. (1997). Metacognitive awareness and second language listeners. ELT Journal, 51(4), 361-369. DOI.org/10.1093/ elt/51.4.361.

Goh, C. (2010). Listening as process: Listening materials for selfappraisal and self-regulation. In N. Harwood (Ed.), English language teaching materials: Theory and practice (pp. 179-206). Cambridge: Cambridge University Press.

Golato, A. (2005). Compliments and compliment responses: Grammatical structure and sequence organization. The Netherlands: John Benjamins.

Hall, S. (1987). 'Minimal selves' in identity: The real me. ICA Document 6. London: Institute for Contemporary Arts.

Hester, S., \& Eglin, P. (1997). Culture in action: Studies in membership categorization analysis. Washington, D.C.: International Institute for Ethnomethodology and Conversation Analysis \& University Press of America.

Holliday, A. (2005). The struggle to teach English as an International Language. Oxford: Oxford University Press.

Kasper, L. (1997). Assessing the metacognitive growth of ESL student writers. TESL-EJ: The Electronic Journal for English as a Second Language, 3(1). http://www.tesl-ej.org/wordpress/ issues/volume3/ej09/ej09a1/?wscr 
Lerner, G. H. (1996). On the "semi-permeable" character of grammatical units in conversation: Conditional entry into the turn space of another speaker. In E. Ochs, E. A. Schegloff, \& S. A. Thompson (Eds.), Interaction and grammar (pp. 238-276). Cambridge: Cambridge University Press.

Matthews, J., \& Sidhu, R. (2005). Desperately seeking the global subject: International education, citizenship and cosmopolitanism. Globalisation, Societies and Education, 3(1), 49-66.

Ochs, E. (1993). Constructing social identity: A language socialization perspective. Research on Language and Social Interaction, 26(3), 287-306.

Penuel, W. R., \& Wertsch, J. V. (1995). Vygotsky and identity formation: A sociocultural approach. Educational Psychologist, 30(2), 83-92.

Pomerantz, A. (1984). Agreeing and disagreeing with assessments. In J. M. Atkinson \& J. Heritage (Eds.), Structures of social action: Studies in conversation analysis (pp. 152-163). Cambridge: Cambridge University Press.

Richardson, K., \& Hurworth, R. (2007). Moving towards independence: International student needs beyond the classroom. Paper presented at the 18th ISANA international education conference, November 27-30, Stamford Grand, Glenelg, Adelaide.

Sacks, H. (1972). On the analyzability of stories by children. In J. J. Gumperez \& D. Hymes (Eds.), Directions in sociolinguistics: The ethnography of communication (pp. 325-345). New York: Rinehart \& Winston.

Sacks, H. (1995). Lectures on conversation. Oxford, UK: WileyBlackwell.

Stafford, G. (2004). Accumulating cultural capital? Some lessons from history for understanding mainland Chinese students in Australian high schools. Asia examined: Conference proceedings of the 15th biennial conference of ASAA, Canberra, Australia, pp. $11,92$.

Stokoe, E. H., Benwell, B., \& Attenborough, F. (2013). University students managing engagement, preparation, knowledge and achievement: Interactional evidence from institutional, domestic and virtual settings. Learning, Culture and Social Interaction, 2(2), 75-90.

Stokoe, E. H., \& Edwards, D. (2006). Story formulations in talk-ininteraction. Narrative Inquiry, 16(1), 56-65. 
Vandergrift, L., \& Goh, C. (2012). Teaching and learning second language listening: Metacognition in action. New York: Routledge.

Vygotsky, L. (1978). Mind in society: The development of higher psychological processes. Cambridge, Mass: Harvard University Press.

Wang, J. (2016). Capitalising on well-roundedness Chinese students' cultural mediations in an elite Australian school. In A. Koh \& J. Kenway (Eds.), Elite schools: Multiple geographies of privilege (pp. 33-49). NY: Routledge.

Anna Filipi is a senior lecturer at Monash University. She teaches in the Languages and TESOL programmes in the Faculty of Education. Her research interests include Conversation Analysis, interactional properties of first and second language acquisition and learning, early childhood interaction, classroom interaction, bilingualism, language assessment, and spatial discourse.

Anna.Filipi@monash.edu 